\title{
Antidiabetic therapy in real practice: indicators for adherence and treatment cost
}

\author{
This article was published in the following Dove Press journal: \\ Patient Preference and Adherence \\ 13 September 2012 \\ Number of times this article has been viewed
}

\section{Giorgio L Colombo ${ }^{1,2}$ \\ Elisa Rossi ${ }^{4}$ \\ Marisa De Rosa ${ }^{4}$ \\ Danilo Benedetto 3 \\ Antonio V Gaddi ${ }^{3}$}

'School of Pharmacy, Department of Drug Sciences, University of Pavia, Pavia, ${ }^{2}$ S.A.V.E. Studi Analisi Valutazioni Economiche, Milan, ${ }^{3} \mathrm{CINECA}$ - Bologna; ${ }^{4}$ Centro Aterosclerosi GC Descovich, Dipartimento di Medicina Interna e dell'Invecchiamento, University of Bologna, Bologna, Italy
Correspondence: Giorgio L Colombo S.A.V.E. Studi Analisi Valutazioni Economiche, Via Previati 74,

20149 Milano, Italy

$\mathrm{Tel}+3902485$ I 9230

Fax +390273960369

Email giorgio.colombo@savestudi.it
Background: Type 2 diabetes has become a disease with a high economic and social impact. The ARNO Observatory is a clinical data warehouse consisting of a network of local health care units (ASL) scattered throughout the Italian territory which collects data on health care consumption for about 10.5 million people. The purpose of this study was to evaluate the use of antidiabetic drugs with particular reference to type of treatment. The analyses were carried out on a sample of 169,375 patients treated with oral blood glucose-lowering drugs in 2008 from a total population of 4,040,624 health care beneficiaries at 12 local health care units in the ARNO Observatory.

Methods: Patients were considered "on treatment with oral blood glucose-lowering drugs" if they had received at least one prescription of an antidiabetic drug (Anatomical Therapeutic Chemical code A10B) during 2008. The patients were divided into three treatment groups, ie, monotherapy, fixed-combination drugs, and dual therapy. The following indicators were assessed: number of patients treated with an oral antidiabetic drug, mean number of hospitalizations, mean number of specialist examinations, and mean expenditure per treated patient. Adherence was assessed using the medication possession ratio indicator (MPR).

Results: Patients treated with oral blood glucose-lowering drugs comprised $4.2 \%$ of the investigated population, and had an average age of 68.9 years. The mean annual number of hospitalizations was lower in the dual therapy group (298 versus 328 per 1000 patients in the sample), while the average number of specialist examinations was lower in the fixed-combination group (30.1 versus 35.1). Patients on monotherapy showed a better percentage of adherence for glimepiride $(70.5 \%)$ and pioglitazone $(70.4 \%)$, whereas the best adherence in the fixedcombination therapy group was recorded for metformin + pioglitazone $(75.5 \%)$. The average annual cost per diabetic patient was $€ 2388$, with differences between the monotherapy ( $€ 2321)$, fixed-combination (€2270), and dual therapy (€2465) groups. Fixed combination therapy involved a lower mean expenditure for insulin, other drugs, and specialist and diagnostic care. Thiazolidinediones (such as pioglitazone) showed the lowest average annual cost per patient among the monotherapies, with a marked decrease in costs for hospitalization, specialist care, and diagnostics.

Conclusion: The results of our study should be extended to other regional/national reference local health care units in order to define and compare average standard costs per pathology throughout the wide sample considered in this research work. Appropriate drug prescribing is of critical importance in order to achieve therapeutic objectives and to optimize the use of resources in modern health care systems.

Keywords: type 2 diabetes, oral antidiabetic drugs, pharmacoeconomics, health care costs, adherence, medication possession ratio 


\section{Introduction}

In recent years, type 2 diabetes has become a disease with a high economic and social impact. ${ }^{1}$ The prevalence and incidence of this disease are rapidly increasing worldwide as a consequence of population ageing, changes in eating habits, and an increasingly sedentary lifestyle. The most recent prevalence estimates carried out in single Italian regions and provinces indicate that about $5 \%-6 \%$ of the country's adult population suffers from diabetes, corresponding to about 3 million people. ${ }^{1}$ Diabetes is a very costly disease because it tends to be associated with the development of complications with time needing an increase in resources, with a heavy impact on health care expenditure. ${ }^{2}$ The Cost of Diabetes in Europe-Type II study was carried out in 2008, prompted by the need of eight European countries (Belgium, France, Germany, Italy, The Netherlands, United Kingdom, Spain, Sweden) to estimate the costs of managing patients with the disease, its complications, and patient quality of life. $^{2}$

The results showed that, on average, a diabetic patient consumed almost $€ 3000$ a year in health care resources. More than half of these resources (59.8\%) were accounted for by hospitalizations, $18.5 \%$ by outpatient care, and $21.7 \%$ by drug therapy. The total cost of treating complications greatly exceeded the cost of treatment of diabetes itself. The presence of one or more complications more than doubled the average cost per diabetic patient. The diabetic population consumed up to $6.65 \%$ of the entire public and private national health care expenditure. The average cost of assisting diabetic patients was more than double (221\%) the average per capita health care expenditure. The local health care units in Brescia $^{3}$ recently monitored organizational, economic, and health indicators, with particular reference to the diabetic population, with very similar results. They found an average annual cost per diabetic patient of $€ 2839$, but if the subject only suffered from diabetes in its isolated form and had no other risk factors, the cost dropped to $€ 892$, ie, to about one third. The presence of an additional risk factor such as dyslipidemia increased the cost by $50 \%$, mainly due to greater use of drugs. Indeed, this cost progressively increased, reaching $€ 6365$ with the combination of four diseases.

Progressive aging of the population and the concomitant increase in chronic degenerative diseases, such as diabetes, are putting ongoing stress on the financing of public health care expenditure in Italy. In the context of reduction and optimization of national health care expenditure, health care service units have developed tools for monitoring health care and drug expenditure, ${ }^{4}$ with the aim of constantly controlling expenditure by health care professionals and assessing the achievement of targets in national and regional health care planning. 5

The ARNO Observatory was activated over 20 years ago as a collaboration between CINECA (Cineca is a non profit Consortium, made up of 54 Italian universities) and the pharmaceutical services of local health care units (ASL), with the aim of creating a database for clinical and health care planning, keeping the patient at the center of the process. ${ }^{6}$ The ARNO Observatory supplies partnered local health care units with a clinical data warehouse on populations and problems, integrating individual patient data derived from various administrative databases (national health care system) on prescriptions to the single citizen, hospital discharge forms, specialist outpatient examinations, personal details, and sociodemographic data. At this time, the ARNO Observatory is made up of a network of 32 local health care units scattered nationwide and collects data on about 10.5 million citizens.

The possibility of exploiting and analyzing the ARNO Observatory database, so rich in information on drug prescriptions, is a unique opportunity to investigate the profile of antidiabetic drug prescriptions in a large patient population, the gap between "what should be done" (suggested by guidelines) and "what is actually done" in real clinical practice, and the economic commitment indicated by the prescription profiles. Analysis of the available information in this regard may be critical in the management, planning, and, if necessary, rationalization of health care expenditure. These resources and their integration are a powerful tool which can be used to support conventional research methods used in epidemiological studies. ${ }^{7}$ Indeed, administrative databases offer low-cost information (because they are already available) regarding nearly all services provided in the health care environment. The aim of this study was to assess the use of antidiabetic agents with particular reference to the type of therapy (monotherapy, dual therapy, fixed combination) in patients enrolled in the ARNO Observatory in terms of:

- characteristics of patients on treatment with antidiabetic agents

- the various therapies (monotherapy, dual therapy, fixed combination)

- adherence to therapy and any differences in adherence between prevalent and incident patients, ie, those who did not take antidiabetic agents in the 4 years before enrolment 
- patient costs for the three therapeutic strategies, including both antidiabetic and concomitant therapy.

\section{Materials and methods Sources of information}

The analyses were carried out in a sample of 169,375 patients treated with oral blood glucose-lowering drugs during 2008 from a population of 4,040,624 health care beneficiaries at 12 local health care units in the ARNO Observatory sample. The available data concerned drugs prescribed for patients and paid for by the national health system, drugs directly supplied to patients by local health care units, and drugs supplied by hospitals through local pharmacies (DPC), both at enrolment and during the follow-up period (Figure 1). To assess patient costs for the three therapeutic strategies, we also used data on hospital discharges and outpatient specialist examinations available for a local health care unit subsample (population about 2 million people). Local health care units were selected based on the simultaneous presence of these data at the time of processing (January to March 2011).

\section{Inclusion criteria for sample}

Patients were considered to be "on treatment with oral blood glucose-lowering drugs" if they had received at least one prescription of an antidiabetic drug (Anatomical Therapeutic Chemical [ATC] code A10B) during 2008. The nature of the first prescription and of later follow-up prescriptions for patients thus identified were recorded in the enrolment and follow-up

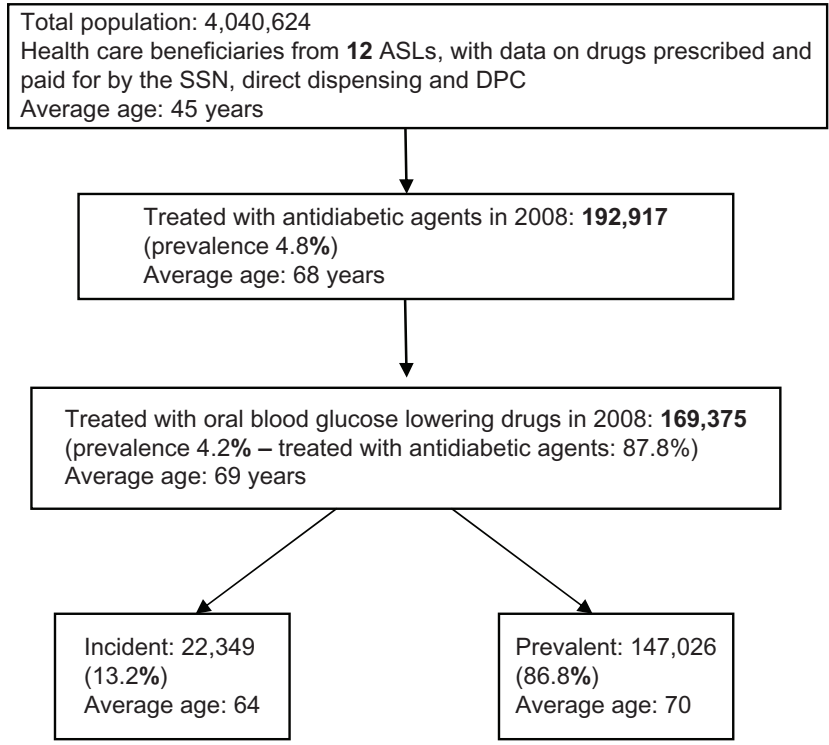

Figure I Procedure and criteria for selection of sample.

Abbreviations: ASL, local health care units; DPC, drugs supplied by hospitals through local pharmacies; SSN, National Health Service. periods. For some local health care units, we cross-checked the available data flows on hospitalizations and outpatient specialist care and diagnostics, recording any concomitant diseases and nursing load. The analysis excluded drugs dispensed in hospitals and in nursing homes. To assess consumption, we took into consideration the number of packs sold (pieces), gross total expenditure, and defined daily dose (DDD). These consumption indicators have been reported in selected cohort of patients treated with oral blood glucose-lowering drugs. Patients were then divided into treatment groups based on the first blood glucose-lowering therapy prescribed during the enrolment period.

The enrolment period was from January 1, 2008 to December 31, 2008, and the follow-up period for each patient was the 12 months following the antidiabetic agent prescription date in the enrolment period (ie, the last possible follow-up date was December 31, 2009). It was also possible to assess the period before each patient's enrolment, ie, the 4 years prior to the first antidiabetic prescription date in the inclusion period (the last possible date for the previous period was January 1, 2004).

\section{Stratification according to treatment group}

Patients were divided into three treatment groups based on the first blood glucose-lowering agent prescribed during the enrolment period, ie, monotherapy, fixed-combination therapy, and dual therapy. Patients with a first prescription of only one of the drug groups in Table 1 were included in the monotherapy group, which also includes patients who started a monotherapy ATC and then switched to another monotherapy ATC during the follow-up period (Table 1).

Patients with first prescription of a drug in the ATC A10BD group (combinations of oral blood glucose-lowering drugs, Table 1) and who continued on a fixed combination throughout the entire follow-up period were included in the fixed-combination group.

Finally, patients with a first and second prescription for oral blood glucose-lowering agents and an overlapping period of at least 15 days were included in the dual therapy group. In this group, some patients may have started dual therapy and gone on to monotherapy or fixed-combination therapy, or changed their type of dual therapy. This definition is consistent with the indications reported in the study by Cheong et al. ${ }^{8}$

\section{Definition of indicators and statistical analysis}

Adherence was measured using the medical possession ratio (MPR), which was calculated as the ratio of treatment units 
Table I Groups of drugs considered for monotherapy and fixed combination divided by ATC code

\begin{tabular}{|c|c|c|}
\hline Drug group & ATC code & Kind of dispensing \\
\hline \multicolumn{3}{|l|}{ Monotherapy } \\
\hline Thiazolidinediones (pioglitazone, rosiglitazone) & AIOBG & Directly dispensed or DPC, as well \\
\hline Sulfonamides, urea derivatives & AIOBB & Drugs prescribed to patients and paid for by the SSN \\
\hline \multicolumn{3}{|l|}{ (glimepiride, glipizide, etc ...) } \\
\hline Biguanides (metformin, fenformin ...) & AIOBA & Drugs prescribed to patients and paid for by the SSN \\
\hline Dipeptidyl peptidase 4 (DPP-4) inhibitors & $\mathrm{AIOBH}$ & Directly dispensed or DPC \\
\hline \multicolumn{3}{|l|}{ (vildagliptin, sitagliptin ...) } \\
\hline Other blood glucose lowering drugs & AIOBX & Drugs prescribed to patients and paid for by the SSN \\
\hline \multicolumn{3}{|l|}{ (repaglinide, exenatide ecc ...) } \\
\hline Alpha glucosidase inhibitors (miglitol ...) & $\mathrm{AIOBF}$ & Drugs prescribed to patients and paid for by the SSN \\
\hline \multicolumn{3}{|l|}{ Fixed combinations } \\
\hline Fenformin and sulfonamides & AIOBDOI & Drugs prescribed to patients and paid for by the SSN \\
\hline Metformin and sulfonamides & AlOBD02 & Drugs prescribed to patients and paid for by the SSN \\
\hline Metformin and rosiglitazone & AIOBD03 & Directly dispensed or DPC, as well \\
\hline Glimepiride and rosiglitazone & AIOBD04 & Directly dispensed or DPC, as well \\
\hline Metformin and pioglitazone & AlOBD05 & Directly dispensed or DPC, as well \\
\hline Glimepiride and pioglitazone & Al0BD06 & Directly dispensed or DPC, as well \\
\hline Metformin and sitagliptin & AlOBD07 & Directly dispensed or DPC only \\
\hline Metformin and vildagliptin & AI0BD08 & Directly dispensed or DPC only \\
\hline
\end{tabular}

Abbreviations: ATC, Anatomical Therapeutic Chemical; DPC, drugs supplied by hospitals through local pharmacies; SSN, National Health Service.

dispensed in the 365 follow-up days to the first prescription, and was estimated for patients who continued with their initial therapy throughout follow-up. Adherence was assessed as: ${ }^{8,9}$

$$
\text { MPR }=\text { total days of drug supply }
$$

Number of days between the first and last prescription (+days covered by the last prescription).

For patients on dual therapy, we used the dual therapy medication possession ratio (DTMPR) indicator, calculated as follows:

$$
\text { DTMPR }=\text { total days of supply of both drugs } / 2
$$

Number of days between the first and last prescription (+days covered by the last prescription).

In order to assess the period covered by each drug, we used defined daily doses with the following formula:

Number of total defined daily doses

$=($ Number of dosage units $\times$

Quantity of active ingredient/defined daily dose) $\times$ Number of prescribed packs.

In accordance with the study by Cheong et al, ${ }^{8}$ a patient is deemed to be adherent when their MPR is $\geq 80 \%$. If MPR exceeded $100 \%$, the value was cut to 100 .

For the population description, we used the following indicators:

- patients treated, ie, health care beneficiaries who received at least one drug prescription in the reference year (national health system prescription sent to a pharmacy in the local health care unit of reference)

- prevalence (treated/beneficiaries $\times 100$ ), ie, the percentage of patients treated with any drug in relation to the total number of beneficiaries

- packs, ie, number of packs collected by a patient from the pharmacy, and mean number of packs per treated patient, ie, number of packs in relation to number of treated patients

- mean number of hospitalizations, ie, the ratio between number of hospitalizations or day hospital visits and number of patients treated with oral antidiabetic agents

- mean number of specialist examinations, ie, ratio between number of specialist examinations (such as laboratory tests, specialist visits, and rehabilitation) and number of patients treated with at least one oral antidiabetic agent

- mean expenditure per treated patient, ie, total expenditure in relation to number of treated patients, representing the annual cost per single treated patient; the value for expenditure is derived from gross expenditure on drugs from pharmacies, DRG for hospitalizations, and examination costs

- defined daily dose per 1000 persons per day, ie, number of defined doses consumed daily by 1000 citizens.

A descriptive statistical analysis was carried out to summarize the parameters for examination proposed above and assessed among the various treatment groups. The variables were studied with descriptive statistical methods, including percentages of total sample, means, and frequencies. 
Table 2 Characteristics of patients treated with oral blood glucose-lowering drugs by treatment group

\begin{tabular}{|c|c|c|c|c|}
\hline Descriptive characteristics & $\begin{array}{l}\text { Patients treated with oral } \\
\text { blood glucose lowering drugs }\end{array}$ & Monotherapy & $\begin{array}{l}\text { Fixed } \\
\text { combination }\end{array}$ & Dual therapy \\
\hline \multirow[t]{2}{*}{ No of patients with diabetes* } & 169,375 & 91,816 & 31,674 & 19,573 \\
\hline & & $54.2 \%$ & $18.7 \%$ & $11.6 \%$ \\
\hline Prevalence & $4.2 \%$ & $2.3 \%$ & $0.8 \%$ & $0.5 \%$ \\
\hline Female & $3.9 \%$ & $2.2 \%$ & $0.7 \%$ & $0.4 \%$ \\
\hline Male & $4.5 \%$ & $2.4 \%$ & $0.8 \%$ & $0.5 \%$ \\
\hline Average age & 68.9 & 68.3 & 71.9 & 67.5 \\
\hline$\%$ of females & $49.1 \%$ & $49.8 \%$ & $49.4 \%$ & $47.0 \%$ \\
\hline Mean no of prescribed packs/year & 72.5 & 66.6 & 71.2 & 86.8 \\
\hline For oral blood glucose lowering drugs & 17.7 & 13.1 & 16.4 & 31.4 \\
\hline For insulin & 1.0 & 1.0 & 1.0 & 1.0 \\
\hline For other drugs & 54.8 & 53.6 & 54.7 & 55.5 \\
\hline DDD 1000 persons/day & 175.6 & 85.2 & 32.2 & 26.1 \\
\hline For oral blood glucose lowering drugs & 40.8 & 14.6 & 7.3 & 9.6 \\
\hline For insulin & 3.9 & 2.2 & 0.7 & 0.5 \\
\hline For other drugs & 134.8 & 70.6 & 24.9 & 16.4 \\
\hline $\begin{array}{l}\text { Mean no of hospitalization/year } \\
\text { (per } 1000 \text { patients) }\end{array}$ & $328 \% 。$ & $328 \%$ & $314 \%$ & $298 \%$ \\
\hline Mean no of specialist examinations/year & 35.1 & 34.0 & 30.1 & 38.6 \\
\hline
\end{tabular}

Notes: *The 169,375 patients include both the sum of patients in monotherapy, fixed combination and dual thearpy $(\Sigma=143,063)$, and patients in mixed therapy: $(\mathrm{N}=26,3 \mid 2)$.

Abbreviation: DDD, defined daily dose.

\section{Results}

Table 2 shows the characteristics of patients treated with oral blood glucose-lowering drugs according to treatment group. It is noteworthy that the total of 169,375 patients also includes patients on mixed therapy $(\mathrm{n}=26,312)$ who switched from monotherapy to dual therapy (22,890 patients, $13.5 \%)$, and those who switched from monotherapy to fixed combinations and vice versa (3422 patients, 2.0\%). The percentage of patients treated with any drug is $4.2 \%$, and they had an average age of 68.9 years. The mean annual number of hospitalizations was lower in the dual therapy group, but this group also had a younger mean age ( 67.5 years) than the total sample. The mean number of specialist examinations was lower in the fixed combination group (30.1 versus 35.1 of the sample). Figure 2 shows the prevalence of consumption per age and gender, and the higher prevalence of men than women is noteworthy.

Figure 3 shows the adherence to monotherapies, with adherence to active ingredients assessed according to the prescription dates of each active ingredient. We found a better percentage of adherence for glimepiride $(70.5 \%)$ and pioglitazone (70.4\%) among the monotherapies, whereas the best adherence in the fixed combination therapy group was recorded for metformin + pioglitazone $(75.5 \%)$. To avoid errors in interpretation of adherence with therapy, we excluded active ingredients used by fewer than 100 patients in the database. Figure 4 shows monotherapies per single active ingredient. Of note, the lower mean annual cost for thiazolidinedione monotherapies (including pioglitazone) which, in spite of their higher cost as oral blood glucose-lowering

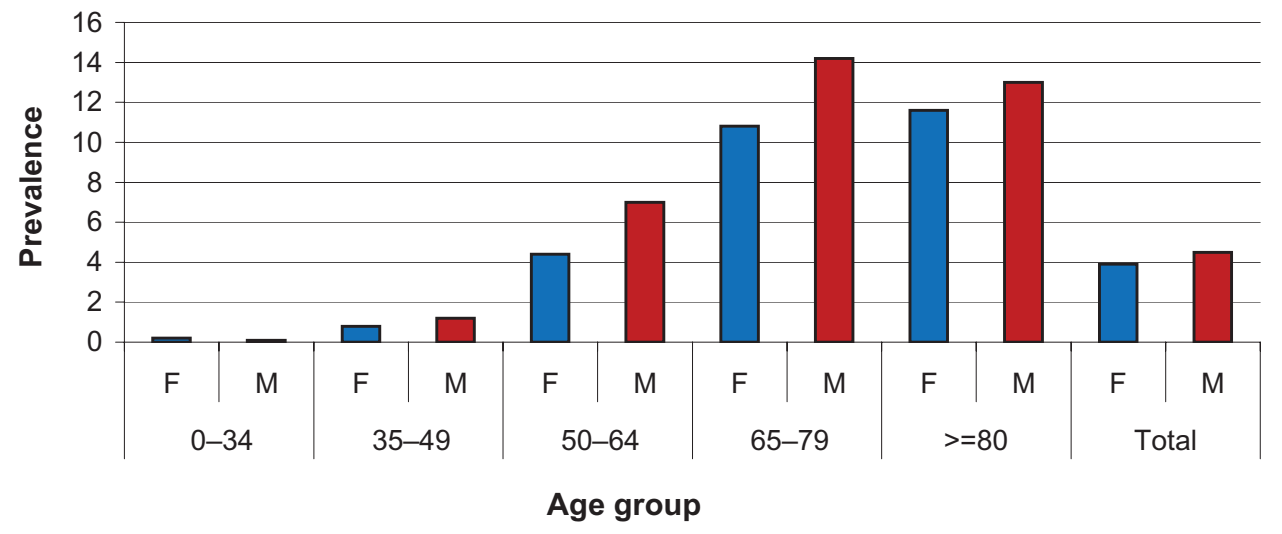

Figure 2 Prevalence of oral blood glucose-lowering drug consumption by age and gender. 


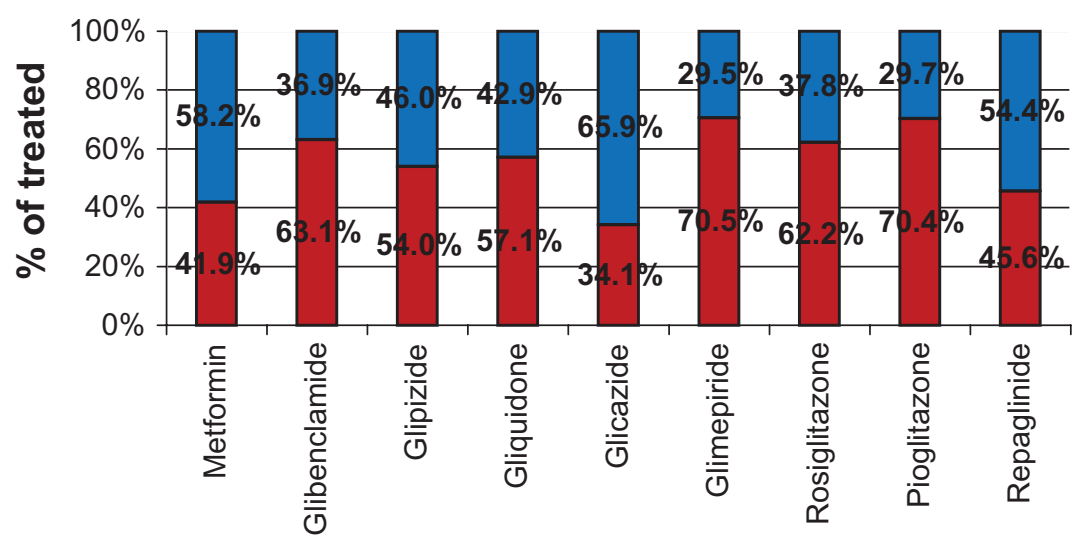

Figure 3 Monotherapy: adherence by type of therapy and active ingredient.

drugs, show a much lower cost for hospitalization and specialist and diagnostic care.

Tables 4 and 5 show the mean total annual cost per diabetic patient divided into the different expenditure categories (drugs from community pharmacies, hospital diagnosisrelated groups, and specialist and diagnostic care). The average annual cost per diabetic patient was $€ 2388$, with differences between monotherapy ( $€ 2321)$, fixed combination (€2270), and dual therapy (€2465). The lower cost for fixed combination therapy is mostly due to the lower mean cost of insulin, other drugs, and specialist and diagnostic care, in spite of the higher cost of oral blood glucose-lowering drugs.

\section{Discussion}

Because the burden of type 2 diabetes is significant in terms of social and health care costs, it was deemed necessary to verify consumption patterns for oral antidiabetic drugs in terms of appropriateness and sustainability of expenditure in clinical practice. Administrative databases offer low-cost information and, unlike other systems used for monitoring and assessment of quality of care, they do not require additional investment in terms of resources. ${ }^{5}$ Data contained in administrative databases are a by-product of economic and administrative operations, so characterize patients as "consumers" of health care system services (drugs, specialist visits, diagnostic tests, hospital admissions). Assessment of drug utilization carried out using the ARNO Observatory database enabled us to determine consumption and prescription terms for an important sample of the diabetic population, to define total and per capita costs for type 2 diabetes, and to suggest policies aimed at implementing expenditure appropriateness and optimization by detecting benchmarks between districts, physicians, different time periods, consumption by age and gender, and geographic distribution of the disease. ${ }^{6}$

However, it is important to highlight that use of administrative databases has some limitations. The data collected come directly from pharmacy invoices, so they provide a true estimate of dispensed medications but not of actual prescriptions written by doctors. The main limitation of administrative databases is indeed the lack of clinical data; because they are created for accounting purposes, they omit

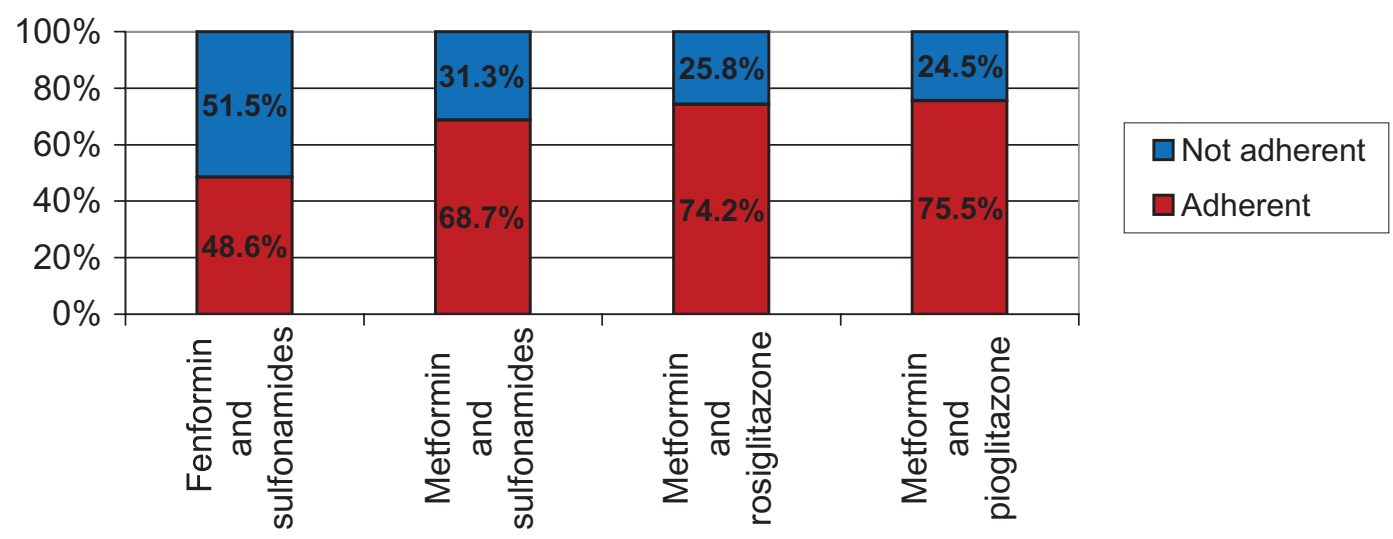

Figure 4 Fixed combination therapy: adherence by type of therapy and active ingredient. 


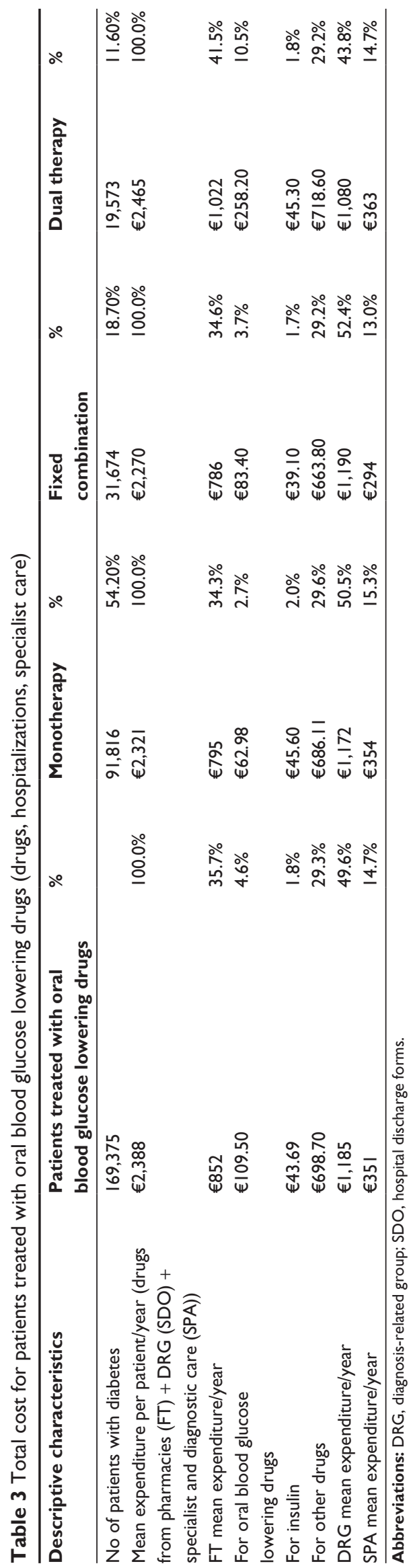

important information on, eg, patient lifestyle, symptoms, diagnoses, and intermediate outcome indicators (ie, vital signs and biochemistry). Furthermore, it should be noted that use of the MPR is an indirect measure of patient adherence, so has the inherent limitations typical of indirect methods of assessment. ${ }^{10}$ For example, during the period of observation, some patients (more than 13\%) appear to have changed their treatment from monotherapy to dual or fixed combination therapy, and the year of diagnosis probably influenced this shift. However, in our administrative database, where the patients were selected as "consumers of antidiabetic therapy", we could not select people with a similar diabetes history in order to address the adherence question better in a homogenous sample.

Measurement and understanding of the concept of adherence with therapy is not only critical for determining the effectiveness and safety of a given drug, but is also important when devising programs aimed at improving quality of drug use. ${ }^{7,11}$ When taking of medication deviates from the prescribed regimen, situation-specific changes in the risk/benefit ratio can arise, with a decreased benefit, an increased risk, or both. ${ }^{7,12} \mathrm{~A}$ number of studies have demonstrated that inadequate adherence (how far the patient follows the prescribed regimen of doses and administration intervals) and persistence (duration of time between beginning and discontinuing therapy) results in increased morbidity and mortality for a wide variety of diseases, and at the same time, significantly increases costs related to health management.

The data analyzed in this study suggest better adherence, as measured by MPR, for pioglitazone, both as monotherapy (70.4\% of treated patients) and as part of a fixed combination (75.5\%). Disregarding the different definitions given in the literature, the major determinants of adherence and persistence are drug tolerability, perception of need/usefulness of a treatment by the patient, willingness to take medication, and patient age and gender. Some technical, behavioral, educational, social support, and structural interventions seem to improve patient adherence and persistence with therapy. ${ }^{11}$

It is also important to remember that in the control and monitoring of diabetic patients, physicians have not only a "clinical" role, but often need to deal with epidemiologic, management, and organizational issues which are necessary for staging, monitoring, and control of the disease process. In this respect, it seems important to gain experience with, eg, the chronic care management model under way in regions including Lombardy, Tuscany, and Emilia Romagna, which 
Table 4 Total cost for patients treated with oral blood glucose lowering drugs (drugs, hospitalizations, specialist care) by macrocategories of antidiabetic agents (ATC Code level 4)

\begin{tabular}{|c|c|c|c|c|}
\hline & \multicolumn{4}{|c|}{ Patients in monotherapy } \\
\hline & $\begin{array}{l}\text { AlOBA } \\
\text { Average age: } 65 \\
\text { Biguanides }\end{array}$ & $\begin{array}{l}\text { AlOBB } \\
\text { Average age: } 73 \\
\text { Sulfonylureas }\end{array}$ & $\begin{array}{l}\text { A IOBG } \\
\text { Average age: } 65 \\
\text { Thiazolidinediones }\end{array}$ & $\begin{array}{l}\text { AlOBX } \\
\text { Average age: } 74 \\
\text { Other }\end{array}$ \\
\hline No of patients with diabetes & 54,886 & 33,594 & 937 & 7,238 \\
\hline $\begin{array}{l}\text { Mean expenditure per patient/year (drugs from pharmacies } \\
(\mathrm{FT})+\text { DRG (SDO) + specialist and diagnostic care (SPA)) }\end{array}$ & $€ 2,244$ & $€ 2,037$ & $€ 1,717$ & $€ 2,828$ \\
\hline FT mean expenditure/year & $€ 783$ & $€ 666$ & $€ 799$ & $€ 942$ \\
\hline For oral blood glucose lowering drugs (\% of expenditure) & $€ 50(6.4 \%)$ & $€ 5 ।(7.7 \%)$ & $€ 323(40.4 \%)$ & $€ 137(\mid 4.7 \%)$ \\
\hline For insulin (\% of expenditure) & $€ 63(8.0 \%)$ & $€ 12(1.7 \%)$ & $€ 35$ (4.4\%) & $€ 44(4.7 \%)$ \\
\hline For other drugs (\% of expenditure) & $€ 670(85.6 \%)$ & $€ 603(90.6 \%)$ & $€ 44 \mathrm{I}(55.2 \%)$ & $€ 76 \mathrm{I}(80.8 \%)$ \\
\hline DRG mean expenditure/year & $€ \mathrm{I}, \mathrm{I} \mid \mathrm{2}$ & $€ \mathrm{I}, 077$ & $€ 662$ & $€ \mathrm{I}, 444$ \\
\hline SPA mean expenditure/year & $€ 349$ & $€ 295$ & $€ 256$ & $€ 442$ \\
\hline$\%$ of drugs from local pharmacies & $34.9 \%$ & $32.7 \%$ & $46.6 \%$ & $33.3 \%$ \\
\hline$\%$ of hospital DRG & $49.6 \%$ & $52.8 \%$ & $38.5 \%$ & $51.1 \%$ \\
\hline$\%$ of specialist care & $15.5 \%$ & $14.5 \%$ & $14.9 \%$ & $15.6 \%$ \\
\hline
\end{tabular}

Abbreviations: ATC, Anatomical Therapeutic Chemical; DRG, diagnosis-related group; SDO, hospital discharge forms.

stimulate genuine cooperation between general practitioners and specialists, with the aim of shared responsibility for patients with type 2 diabetes and other diseases through effective management mechanisms. ${ }^{13,14}$

Comparison of the present analysis with a previous study published in $2006^{3}$ involving 37,862 diabetic subjects in the Brescia local health care unit shows that the annual per capita cost in our sample is about $16 \%$ lower ( $€ 2388$ versus $€ 2839$ for the Brescia local health care unit), mainly because of a $27 \%$ drop in hospitalization costs ( $€ 1185$ versus $€ 1612$ for the Brescia local health care unit), but with a concomitant $11 \%$ increase in pharmaceutical expenditure ( $€ 852$ versus $€ 769$ for the Brescia local health care unit). Constant growth in use of innovative drugs, together with traditional drugs with expired patents, probably enabled reduction of treatment costs for type 2 diabetes during the study period. Finally, it is important to highlight the need for further observational studies in this field, using data for real-world drug use and regional administrative databases, to confirm and validate further our results in clinical practice. If diabetes treatment costs continue to increase, and at a higher rate than for global health care expenditure, the availability of tools able to compare data on the use of health care interventions in terms of incremental cost per increment in efficacy clearly become of great importance; it is also necessary to transform such tools in a constant point of reference for the physicians and the health care policy makers choices. Appropriate drug prescription is of critical importance in order to achieve therapeutic objectives and to optimize the use of resources in modern health care systems.

\section{Disclosure}

The authors report no conflicts of interest in this work.

\section{References}

1. World Health Organization. Global status report on noncommunicable diseases, 2010. Geneva, Switzerland: World Health Organization; 2011. Available from: http://www.who.int/nmh/publications/ncd_report_full_ en.pdf. Accessed July 28, 2012.

2. Lucioni C, Garancini MP, Massi-Benedetti M, et al. Per conto dell'Advisory Board Italiano dello Studio CODE-2 (COsts of Diabetes in Europe-type 2). [The social cost of type-2 diabetes mellitus in Italy: the CODE-2 study]. Il costo sociale del diabete di tipo 2 in Italia: lo studio CODE-2. Pharmacoeconomics - Italian Research Articles. 2000;2(1):1-21. Italian.

3. Scarcella $C$, Indelicato A, Levaggi $R$, et al. Il costo del diabete: l'esperienza dell'ASL di Brescia. [The cost of diabetes: the Brescia's experience]. Pharmaco Economics Italian Research Articles. 2006;8(2):95-103. Italian.

4. AIFA - Italian Drug Agency - Gruppo di lavoro OsMed. L'uso dei farmaci in Italia. Rapporto nazionale anno 2010. Roma: Il Pensiero Scientifico Editore, 2011. Available from: http://www.agenziafarmaco.gov.it/it/ content/osservatorio-sull\%E2\%80\%99impiego-dei-medicinali-osmed. Accessed July 28, 2012. Italian.

5. Cerra C, Lottaroli S. Utilizzo di banche dati amministrative per il calcolo dei costi di patologie croniche e/o degenerative. Un metodo per la mappatura dei consumi sanitari degli assisititi dal SSN. [Use of administrative databases for calculating the cost of chronic patologies]. Pharmacoeconomics-Italian Research Articles. 2004;6(3):141-149. Italian.

6. ARNO Observatory. In: Primo Piano. Available from: http:// osservatorioarno.cineca.org/. Accessed July 28, 2012.

7. Casula M, Tragni E, Catapano AL. I database amministrativi come fonti di dati per la ricerca farmaco epidemiologica. [The administrative databases as data sources for epidemiological research drug]. CARE I. 2011: 33-36. Italian.

8. Cheong C, Barner JC, Lawson KA, Johnsrud MT. Patient adherence and reimbursement amount for antidiabetic fixed-dose combination products compared with dual therapy among Texas Medicaid recipients. Clin Ther. 2008;30:1893-1907.

9. Thayer S, Arondekar B, Harley C, Darkow TE. Adherence to a fixeddose combination of rosiglitazone/glimepiride in subjects switching from monotherapy or dual therapy with a thiazolidinedione and/or a sulfonylurea. Ann Pharmacother. 2010;44:791-799. 
10. Osterberg L, Blaschke T. Adherence to medication. $N$ Engl J Med. 2005;4:353:487-497.

11. Borghi C, Cicero AFG. Aderenza e persistenza in terapia. [Adherence and persistence in therapy]. Giornale Italiano di Farmacoeconomia e Farmaco Utilizzazione. 2008;1: 5-13. Italian.

12. Catapano AL, Casula M, Tragni E. Indicatori di appropriatezza prescrittiva per la valutazione della qualità assistenziale. [Appropriateness of prescribing indicators for assessing the quality of care]. CARE. 2010;6:33-35. Italian.
13. Regione Lombaria. CREG Chronic Related Group. Available from: http://www.sanita.regione.lombardia.it/cs/Satellite?c=Redazionale_P \&childpagename=DG_Sanita\%2FDetail\&cid=1213425053169\&pag ename=DG_SANWrapper. Accessed July 28, 2012.

14. Regione Toscana. Piano Sanitario Regionale 2008-2010. Available from: http://www.regione.toscana.it/regione/export/RT/sito-RT/ Contenuti/sezioni/azione_governo/piani_programmi_regionali/ rubriche/opportunita_scadenze/visualizza_asset.html_1852883608. html. Accessed July 28, 2012.

\section{Publish your work in this journal}

Patient Preference and Adherence is an international, peer-reviewed, open access journal focusing on the growing importance of patient preference and adherence throughout the therapeutic continuum. Patient satisfaction, acceptability, quality of life, compliance, persistence and their role in developing new therapeutic modalities and compounds to optimize clinical outcomes for existing disease states are major areas of interest. This journal has been accepted for indexing on PubMed Central. The manuscript management system is completely online and includes a very quick and fair peer-review system. Visit http://www.dovepress.com/ testimonials.php to read real quotes from published authors.

Submit your manuscript here: http://www.dovepress.com/patient-preference-and-adherence-journal 